\title{
Association of Oral Contraceptives and Abnormal Pap Smear
}

\author{
${ }^{1}$ Sayedmohsen Sayednozadi, ${ }^{1}$ Mohammadreza Hassany and ${ }^{2}$ Mohammad Arash Ramezani \\ ${ }^{1}$ Department of Community Medicine and Health, \\ Mashhad Medical School of Mashad Medical Sciences University, Mashad, Iran \\ ${ }^{2}$ Department of Family and Community Medicine, \\ Isfahan Medical School of Isfahan Medical University, Hezarjarib Street, Isfahan, Iran
}

\begin{abstract}
To assess the hypothesis that combined Oral Contraceptive (OCs) increase the risk of cervical neoplasia, we conducted a multicenter Case-Control study in Mashhad, the capital of Khorasan province. Seventy-eight women with moderate to severe dysplasia at Pap smear as case group and one hundred fifty nine women with normal Pap smear were selected as the control group for evaluation. The both case and control groups were matched by age, parity and socioeconomic status. All of the women in this study were single partner as husband and no smoker. 30 percent of cases and 64.8 percent of controls were used OCs. The duration of OCs use was the same in both. The odds ratio for OCs consumption was 0.2 with $95 \%$ confidence interval 0.11-0.4 in Logistic regression analysis. In contrast to some other studies, our findings showed an association between OCs and cervical dysplasia and there was a protective effect of OCs for cervical dysplasia.
\end{abstract}

Key words: Oral Contraceptives (OCs), cervical dysplasia, pap smear, Mashad, Iran

\section{INTRODUCTION}

Initial studies had explained the relationship of Oral Contraceptives (OCs) and cervical neoplasia ${ }^{[1-4]}$ In two extensive reviews, It was conducted that a weak positive association seems to be emerging between OCs usage and the risk of cervical neoplasia but that association may be due to bias and confounding ${ }^{[5,6]}$ In the other studies, this association has fallen into suspicion. Molina and coworkers did not find any risk for neoplasia in women who ever used OCs after controlling for the possible confounder ${ }^{[7]}$. Screening of cervical neoplasia with Papanicolau smear (Pap smear) is very useful for preventing of cervical cancer, it seems confounded for cervical neoplasia itself, because of Human Papilloma Virus (HPV) changes in cervical mucous $^{[8-10]}$. However several Pap smear in 3 to 5 year period have been recommended for every woman, which increased the accuracy ${ }^{[8]}$.

To evaluate the hypothesis that OCs affect to cervical mucus and may create neoplasia, we conducted a multicenter Case-Control study involving patients with moderate to high grade changes in cervical mucus at Pap smear and were compared with controls in Mashad- the capital of Khorasan province.

\section{MATERIAL AND METHODS}

Between 1988 and 2003, cases eligible for this case-control study were selected from women aged 20 to 50 years attending the gynecology clinic of a general hospital (Gaem hospital) and several district health centers of Mashhad city the capital of Khorasan province. Several Pap smear determined the diagnosis of dysplasia (normal, mild, moderate and severe) and all slides were reviewed by a cytopathologist.

Of the 237 women that were entered into our study, 78 women had moderate to severe neoplasia in pap smears as case groups. The control group was matched age and socioeconomic status up together two times over case group, 159 women that had normal Pap smears.

A data collection form sought information on social and status, gynecology and obstetrics history, smoking habits and combined OCs practice. Variable included in the analysis were indices by age, number of parity, number of children and abortion, smoking status and duration of OCs use.

Matched odds ratios were calculated for each significant variable. Multivariable logistic regression was used to adjust for potential confounding variables. Comparisons between groups were examined by Mantel-Haentzel, Chi square and Mann-Whitney tests.

\section{RESULTS}

All 237 women had married and the range of age was 20-50 years. All of them had one partner and most of them had the first of intercourse up 20 years old. Both cases and controls were the same about sexual habits. None of women regarding to study were smoked.

Corresponding Author: Mohammad Arash Ramezani, Department of Family and Community Medicine, Isfahan Medical School of Isfahan Medical University, Hezarjarib Street, Isfahan, Iran Tel: 989131412932 
Table 1: Distribution of OCs consumption in this study sample

\begin{tabular}{lccc}
\hline Group OCs & Control & Case & Total \\
\hline Negative & 56 & 57 & 113 \\
Positive & 103 & 21 & 124 \\
Total & 159 & 78 & 237 \\
\hline Chi square $=30.063, \mathrm{df}=1, \mathrm{p}<0.0001, \mathrm{OR}=0.2,95 \% \mathrm{CI}=0.11-0.36$
\end{tabular}

Table 2: Distribution of duration of OCs consumption in this study sample

\begin{tabular}{lccr}
\hline Group Duration & Control & Case & Total \\
\hline OCs $<=3$ & 104 & 66 & 170 \\
OCs $>3$ & 55 & 12 & 67 \\
Total & 159 & 78 & 237
\end{tabular}

Chi square $=9.52, \mathrm{df}=1, \mathrm{p}=0.002, \mathrm{OR}=0.3595 \% \mathrm{CI}=0.17-0.7$

Table 3: Estimates of the odds ratio and coefficient of equation in the logistics regression* analysis

Variable OR Lower limit Upper limit B coefficient $\quad \mathrm{P}$ value

\begin{tabular}{llllll}
\hline OCs & 0.2 & 0.11 & 0.4 & -1.6078 & $\mathrm{P}<0.0001$ \\
\hline
\end{tabular}

*logistic regression by Forward Wald method

Thirty percent of women in case group and $64.8 \%$ of controls were using combined OCs.

There were marked differences between the cases and controls with regard to OCs use (Table 1). Women with developmental cervical dysplasia had an odds ratio (OR) of 0.2 with $95 \%$ confidence interval (CI): 0.11 0.36 . It was considerable that OCs consumption had a protective effect.

The duration of OCs use was associated with a protective effect of cervical dysplasia, with increasing duration of uses over 3 years. OR was 0.35 with $95 \%$ CI: 0.17-0.7 (Table 2).

To investigate the role of combined OCs use and duration of consumption, logistic regression was performed in which the effect of OCs use was adjusted separately for the cofactor that duration. Other covariables like age and education were matched and smoking, parity and sexual behaviors were the same in the both groups.

The multivariable logistic regression appeared that OCs users were five times more protective for cervical dysplasia. This risk was significant when adjusted with duration and duration of use did not enter into the equation (Table 3 ).

\section{DISCUSSION}

The results of this study were very interesting, because of an effect of OCs not only were at the risk of cervical dysplasia but also had a protective effect and duration of pill consumption didn't effect on this association. It is in contrast to another study. Many studies concluded an association whatever a week positive between OCs use and the risk of cervical dysplasia ${ }^{[5,6,10-}$ ${ }^{12]}$. But more of study emphasized on the relationship between OCs use and cervical cancer ${ }^{[7,13-17]}$.

This association may be due to bias and confounding, like smoking, sexual behavior, socioeconomic status and human Papilloma virus (HPV) infection.
We controlled all confounded except HPV. In Islamic countries, like Iran unlawful relation is very rare and practicing the religious laws causes the family relation and every woman are intercourse with her husband.

The other fact is the very low rate of smoking in Iranian women due to cultural context. Thus these two risk factors are rare in Iran.

The most important limitation of our study was the lack of information about HPV infection, we could not diagnose it in Mashhad. The second, it was better that evaluated cervical neoplasia by biopsies from different part of the cervix.

It is generally accepted that cervical neoplasm is a sexually transmitted disease and many risk factors associated with this cancer ${ }^{[11]}$.

It appears as though that OCs is not risk factor for cervical neoplasia alone; on the contrary the other risks like sexual habits, smoking and especially viral infection fortify this association. HPV is known agent of cervical cancer ${ }^{[18-20]}$. The detection of HPV in women is necessary. However Pap smear is a very good screening which decreases cervical cancer incidence by identifying precursor lesions such as carcinoma in $\operatorname{situ}^{[21,22]}$.

At the end more studies with the controlling of confounder are necessary and our results should examine more and more.

\section{REFERENCES}

1. Boyce, J.G., T. Lu, J.H. Nelson and R.G. Frutcher, 1977. Oral contraceptives and cervical carcinoma. Am. J. Obstet. Gynecol., 128: 761-6.

2. Melamed, M.R. and B.J. Flehinger, 1973. The Early incidence of precancerous cervical lesions in women using contraceptives. Gynecol. Oncol., 1: 290-8.

3. Sandmire, H.F., S.D. Austin and R.C. Bechtel, 1976. Carcinoma of cervix in oral contraceptive steroid and IUD users and nonusers. Am. J. Obstet. Gynecol., 125: 339-45.

4. Worth, A.J. and D.A. Boyes, 1972. A case control study into possible effects of both bills on preclinical carcinoma of the cervix. J. Obstet. Gynecol. Br., 79: 673-9.

5. Brinton, L.A., 1991. Oral contraceptives and cervical neoplasia. Contraception, 43: 581-95.

6. Schlesselman, J.J., 1989. Cancer of the breast and reproductive tract in relation to use of oral contraceptives. Contraception, 40: 1-38.

7. Molina, R., D.B. Thomas, A. Dabancens and et al., 1988. Oral contraceptives and cervical carcinoma in situ in Chile. Cancer Res., 48: 1011-15.

8. Morrison, C., P. Prokoryn, C. Piquero et al, 2003. Oral contraceptive pills are associated with artifacts in a thin prep Pap smear that mimic low grade squamous intraepithelial lesions. Cancer, 99: 75-82. 
9. La Vecchia, C., S. Franceschi, A. Decarli and et al., 1984. Pap smear and the risk of cervical neoplasia. Lancet, 2: 779-82.

10. Gram, I.T., M. Macaluso and H. Stalsberg, 1992. Oral contraceptive use and the incidence of cervical intraepithelial neoplasia. Am. J. Obstet. Gynecol., 167: 40-4.

11. Clarke, E.A., J. Hatcher, G.E. McKeowm-Eyssen and G.M. Lickrish, 1985. Cervical dysplasia: associated with sexual behavior, smoking and Oral contraceptive use? Am. J. Obstet. Gynecol., 151: 612-6.

12. Stubblefield, P.G., 1984. Oral contraceptives and neoplasia. J. Reprod. MED., 29S: 524-9.

13. WHO collaborative study of neoplasia and steroid contraceptives, 1985. Invasive cervical cancer and combined Oral contraceptives. B.M.J., 290: 961-5.

14. Brinton, L.A., W. Reeves, M.M. Brenes and et al., 1990. Oral contraceptive use and risk of invasive cervical cancer. Int. J. Epidemiol., 19: 4-10.

15. Ursin, G., R.K. Peters, B.H. Henderson and et al., 1994. Oral contraceptive use and adenocarcinoma of cervix. Lancet, 344: 1390-4.

16. Zondervan, K.T., L.M. Carpenter, R. Painter and M.P. Vessey, 1996. Oral contraceptives and cervical cancer. Br. J. Cancer, 73: 1291-7.
17. WHO collaborative study of neoplasia and steroid contraceptives, 1996. Oral contraceptives and invasive adenocarcinoma and adenosquamous carcinoma of the uterine cervix. Am. J. Epidemiol., 144: 281-9.

18. Walboomers, J.M., M.V. Jacobs, M.M. Manos and et al., 1999. Human papilloma virus is a necessary cause of invasive cervical cancer worldwide. J. Pathol., 189: 12-19.

19. Bosch, F.X., A. Lorinez, N. Munoz, C.J. Meijer and K.V. Shah, 2002. The causal relation between human papilloma virus and cervical cancer. J. Clin. Pathol., 55: 244-65.

20. Lacey, J.V., L.A. Brinton, F.M. Abbas and et al., 1999. Oral contraceptives as risk factor for cervical adenocarcinoma and squamous cell carcinoma. Cancer Epidemiol. Biomark. Preven., 8: 1079-85.

21. Herrero, R., L.A. Brinton, W. Reeves and et al., 1992. Screening for cervical cancer in Latin America: A case control study. Int. J. Epidemiol., 21: 1050-56.

22. Parrazini, F., E. Negri, E. Ricci, S. Franceschi and C. La Vecchia, 1996. Coraltes of Oral contraceptives in Italian women, Contraception, 54: 101-6. 